\title{
Meningoencefalítis por Angiostrongylus cantonensis Informe de un caso atípico
}

\author{
Ernesto Arteaga', Fidel A. Nuñez ${ }^{1}$, Rogelio Alvarez ${ }^{2}$
}

\begin{abstract}
Resumen
La infección humana por Angiostrongylus cantonensis es conocida mundialmente como una de las principales causas de meningoencefalitis eosinofílica. Este informe corresponde al estudio clínico y anatomopatológico de un paciente fallecido en el Hospital General Calixto García de La Habana, con un cuadro de infección neurológica de evolución tórpida y en el que la autopsia demostró la presencia de este parásito en cerebro y pulmón. Los análisis de laboratorio clínico no revelaron aumento de los eosinófilos en la sangre ni en el líquido cefalorraquídeo. La escasa frecuencia, en nuestro medio, de este parasitismo en el hombre y, sobre todo, su presentación clínica atípica motivaron su información.
\end{abstract}

\section{Summary}

Human infection due to Angiostrongylus cantonensis is well-known throughout the world as being one of the main causes of eosinophilic meningoencephalitis. The present report corresponds to a clinical and anatomopathological study of a patient from the General Calixto García Hospital in Havana, who died from a neurological infection with torpid evolution. Autopsy revealed the presence of this parasite in the brain and lungs. Clinical laboratory tests did not show an eosinophile increase in blood or cerebrospinal fluid. The low frequency of this human parasitic disease in Cuba, as well as its unusual clinical presentation, prompted us to present this atypical report.

Angiostrongylus cantonensis es un nemátodo que vive en las arterias pulmonares de la rata. Cuando un huésped no habitual (incluyendo al hombre) es infectado, el parásito migra hacia el cerebro, pero, en contraste con su hospedero habitual, no alcanza su desarrollo hasta la madurez sexual. Durante la migración del parásito dentro del sistema nervioso central (SNC) en el hombre, se produce un cuadro de meningoencefalitis, caracterizada por su asociación con eosinofilia en sangre y en líquido cefalorraquídeo (LCR) (1).
En 1935, Chen describió por primera vez en Cantón, China, la infección pulmonar de ratas domésticas por este parásito, denominado entonces, Pulmonema cantonensis (2). Diez años más tarde, Nomura y Lin, en Taiwán, describieron la infección humana por Angiostrongylus en una joven de 15 años (3). Posteriormente, la infección fue informada en numerosas islas del océano Pacífico y países del sureste asiático. Actualmente, este parasitismo tiene una distribución mundial diseminada en zonas tropicales y subtropicales

Instituto de Medicina Tropical Pedro Kourí, Ciudad de La Habana, Cuba.

2 Hospital Docente General Calixto García, Ciudad de La Habana, Cuba. 
(4). En la zona del Pacífico, aún continúa siendo la causa principal de meningoencefalitis eosinofílica.

En Cuba, Pascual y colaboradores informaron, en 1981, el hallazgo en La Habana de numerosos casos de meningitis eosinofílica (5), así como la presencia del nemátodo en las arterias pulmonares de ratas atrapadas cerca de los hogares de estos pacientes. Ese mismo año, Aguiar (6) estableció que este nemátodo era $A$. cantonensis, siendo el primer informe de este parasitismo exótico en las Américas.

Nuestro informe corresponde a un caso de evolución tórpida y fatal, con un cuadro neurológico grave que ofreció parámetros de laboratorio atípicos que impidieron un correcto diagnóstico premortem.

\section{Caso clínico}

Se trató de un paciente masculino, de raza mestiza, de 22 años de edad, que estuvo recluido en prisión durante nueve meses, con antecedentes de retraso mental ligero y epilepsia, tipo gran mal, desde los 12 años para lo cual llevaba un tratamiento irregular con fenobarbital, $100 \mathrm{mg}$, dos veces al día. Antes de su reclusión, se señala la ingestión frecuente de bebidas alcohólicas. Las autoridades policiales informaron a los médicos de los inadecuados hábitos alimentarios del paciente, desde los alimentos no cocidos, hasta otros en mal estado de conservación que hallaba en el suelo.

Su enfermedad comenzó con cefalea, anorexia, astenia marcada, odinofagia y fiebre hasta de $39^{\circ} \mathrm{C}$. Posteriormente, se añadió estado confunsional, rigidez de nuca sin signos de focalización neurológica, dolor y contractura abdominal. Se realizó una punción lumbar para el estudio de LCR: células $117 \times 10^{6} / \mathrm{L}$, con predominio de linfocitos; glucosa, 2,4 mmoles/L; proteínas; $0,34 \mathrm{~g} / \mathrm{L}$; Pandy $(++)$. Se instauró tratamiento con penicilina y cloramfenicol por vía endovenosa, considerando la posibilidad de una meningoencefalitis bacteriana modificada. Cinco días después, no se observaba mejoría del cuadro neurológico y se decidió su remisión al Hospital Docente General Calixto García, donde se recibió en estupor profundo con rigidez nucal moderada, hemiparesia derecha con predominio crural y diplopía; escala de Glasgow: 10 puntos; tomografía axial computadorizada (TAC) de cráneo, normal; hemoglobina, $12 \mathrm{~g} / \mathrm{L}$; hematocrito, $30 \mathrm{vol} / \%$; leucocitos, $12,3 \times 10^{9} / \mathrm{L}$; polimorfonucleares neutrófilos, 91 ; linfocitos, 15; eosinófilos, 4; glicemia, 12 mmoles/L. El resto de los exámenes fueron normales.

A pesar del tratamiento impuesto con antibióticos, depletantes de líquidos para el SNC, anticonvulsivos, vitaminoterapia, etc., su estado de conciencia empeoró (Glasgow, 8 puntos) por lo cual se trasladó a la unidad de ciudados intermedios con diagnósticos de: coma de etiología no precisada, posible meningoencefalitis viral o intoxicación exógena. Volvió a presentar fiebre de 37 a $39^{\circ} \mathrm{C}$, nistagmo transitorio y progresó al estado de coma profundo (Glasgow, 3 puntos).

$\mathrm{El}$ aspecto general del paciente era caquéctico, con desnutrición intensa y atrofia muscular generalizada. Aumentaron las secreciones traqueobronquiales, lo cual motivó su intubación y acople a ventilador ciclado por presión; falleció 24 horas después de su ingreso.

Los resultados de los principales análisis de laboratorio fueron los siguientes:

- LCR (citoquímico): Pandy (++); células $210 \mathrm{x}$ 106/L; linfocitos, 96; PMN, 4; proteínas, 0,4 g/ L; algunos eosinófilos; glucosa normal.

- LCR (electroforesis de proteínas): proteínas totales: $123 \mathrm{mg} / \mathrm{dL}$ (cuatro veces su valor normal); ligero incremento de prealbúmina 1 y beta 1; gammaglobulinas, $37,6 \%$ (aumentadas).

- Eritrosedimentación evolutiva: 56-80-112 mm en 1 hora.

- Serología (VDRL y VIH): negativos en dos ocasiones.

- Hemocultvos seriados: negativos.

- Ecocardiograma, normal.

- TAC de cráneo: sistema ventricular pequeño, sin otras alteraciones craneoencefálicas.

El resto de los exámenes realizados fueron normales. 
Múltiples exámenes bacteriológicos y micológicos negativos en LCR.

\section{Hallazgos anatomopatológicos}

En la autopsia, los hallazgos fundamentales fueron en el SNC; consistieron en un engrosamiento y opacidad marcada de las leptomeninges con múltiples zonas pequeñas de hemorragia. La superficie de corte del cerebro y cerebelo mostraron edema y congestión intensa de los vasos.

Histológicamente, el espacio subaracnoideo presentó un infiltrado intenso con predominio de células mononucleares, con leucocitos eosinófilos dispersos. Casi todos los vasos mostraron necrosis fibrinoide de la pared con una reacción granulomatosa a su alrededor y células gigantes de tipo cuerpo extraño (figura 1). Observamos, esporádicamente, adyacentes a los mismos, diversos cortes tranversos o tangenciales de parásitos identificables morfológicamente como nemátodos adultos jóvenes con cambios degenerativos, los cuales son compatibles con $A$. cantonensis (figuras 2 y 3 ).

En las secciones de parénquima cerebral, se observaron nódulos o agregados de células gliales con macrófagos cargados de pigmento (hemosiderina) que podrían corresponder a los trayectos provocados por el parásito durante su migración.

Los pulmones mostraron áreas con inflamación aguda supurada y necrosis, en las cuales se identificó el parásito en vías de degradación dentro de la luz de los vasos sanguíneos (figura 4).

\section{Discusión}

La infección por $A$. cantonensis en el hombre se caracteriza por producir una encefalitis con cuadro clínico proteiforme por la migración errática del parásito a través del SNC. En la mayoría de los casos, la encefalitis está asociada con un incremento importante de los eosinófilos en el LCR (7).

Diversos estudios señalan el papel de los eosinófilos en la patogénesis de esta enfermedad, en la defensa contra los helmintos y la destrucción de los parásitos así como en el control de la respuesta inflamatoria y en el daño hístico $(8,9)$.

En la práctica clínica, no es común el hallazgo de pleocitosis eosinofílica en el LCR; $\sin$ embargo, puede ocurrir en numerosas circuns-

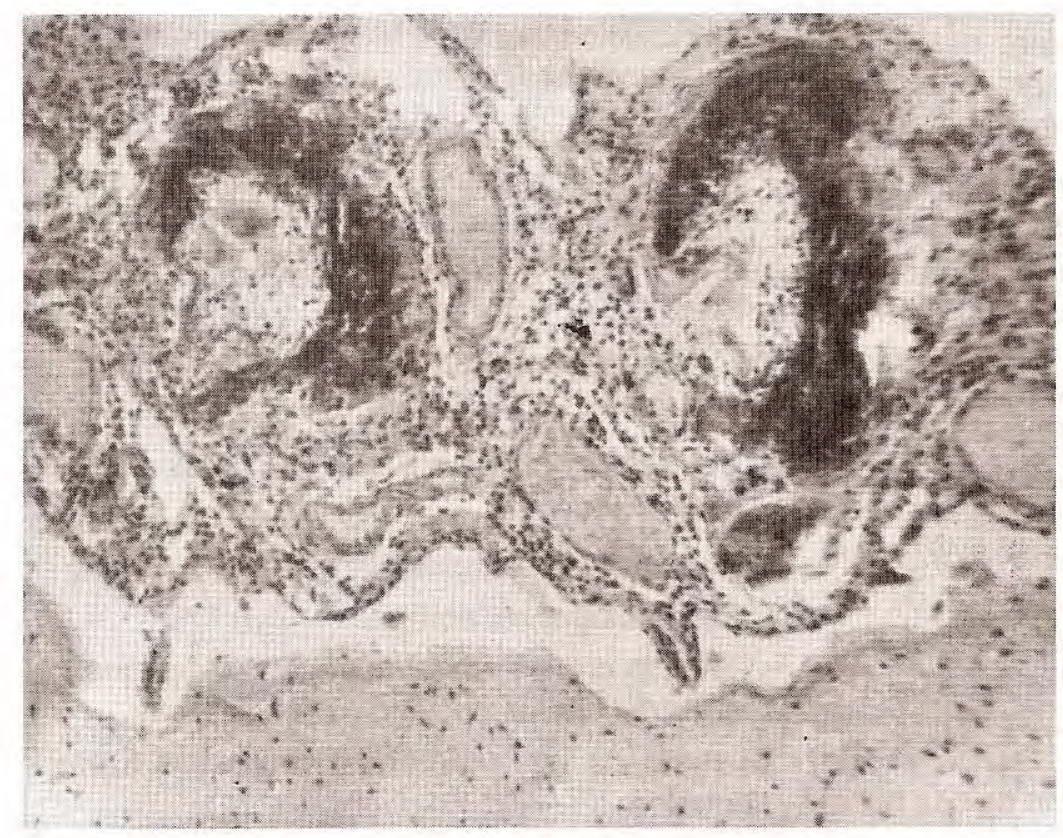

Figura 1. Vasculitis necrotizante con reacción inflamatoria crónica y células gigantes multinucleadas en leptomeninges (HE, 160X). 


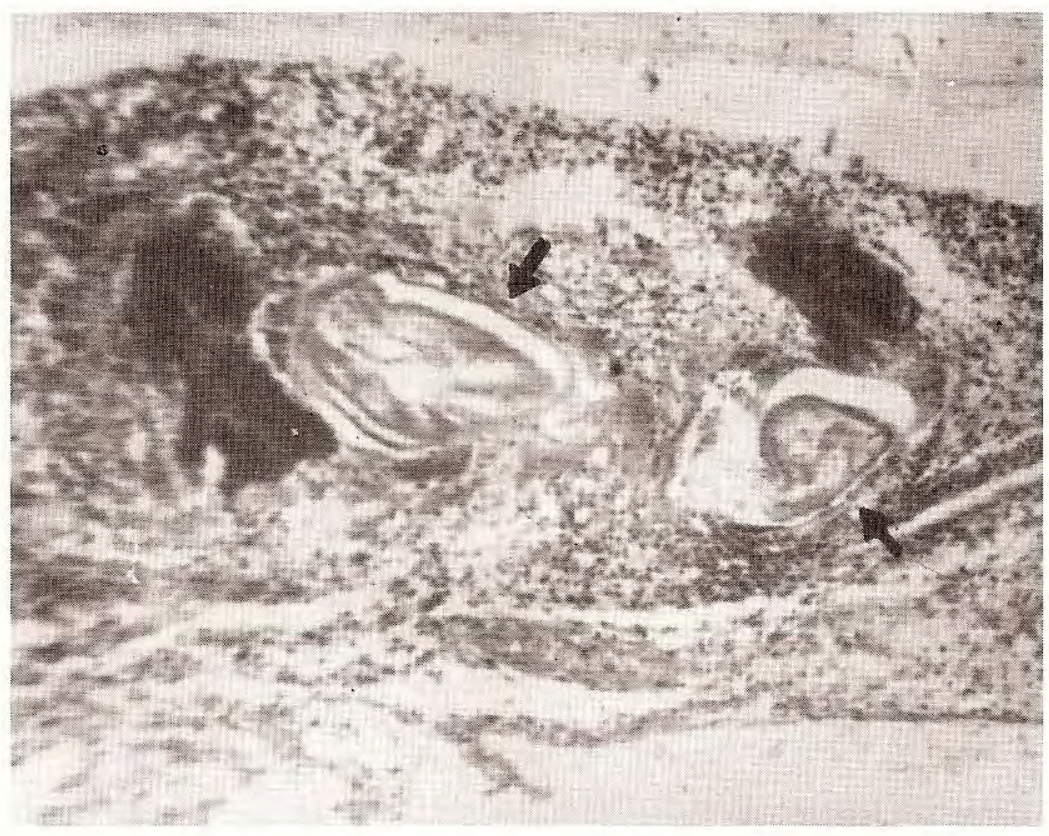

Figura 2. Secciones transversales del parásito cerca de las zonas de necrosis inflamatoria de los vasos meníngeos (HE, 160X).

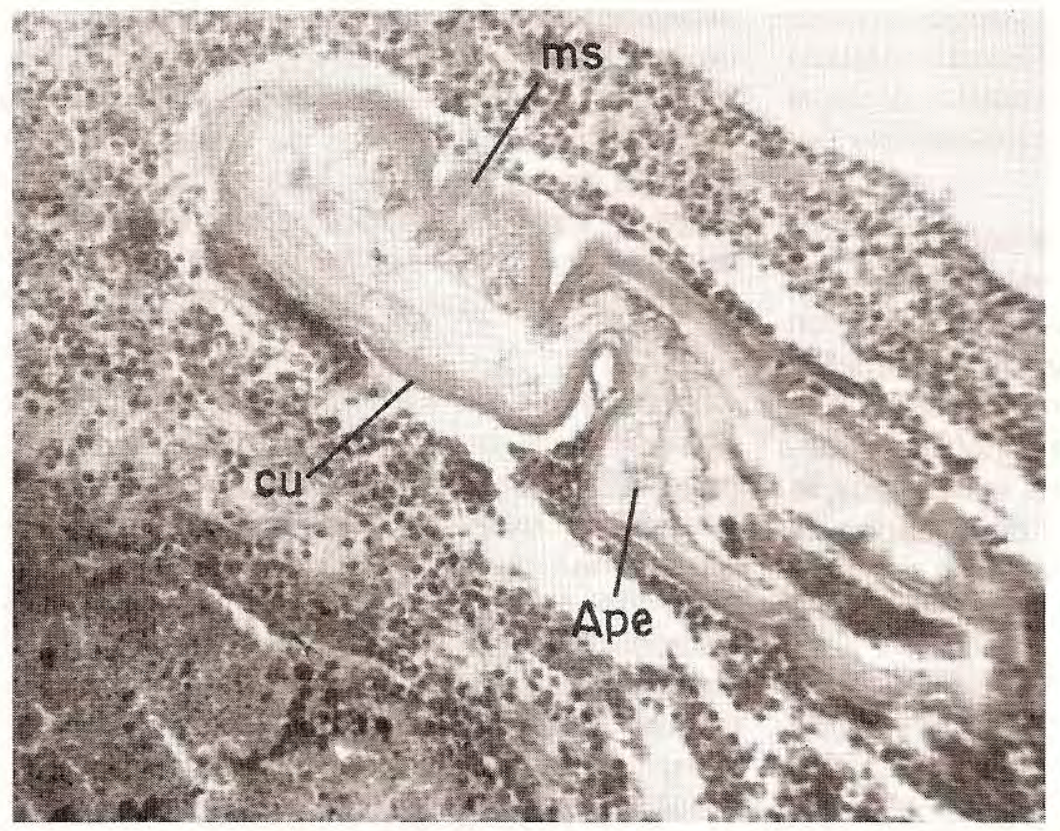

Figura 3. Corte tangencial del parásito adulto con cambios degenerativos, rodeado por un infiltrado de células monoonucleares y algunos eosinófilos (HE, 400X). 
Figura 4. Corte histológico del pulmón donde aparece el parásito en el interior de un vaso (HE, $63 X)$.

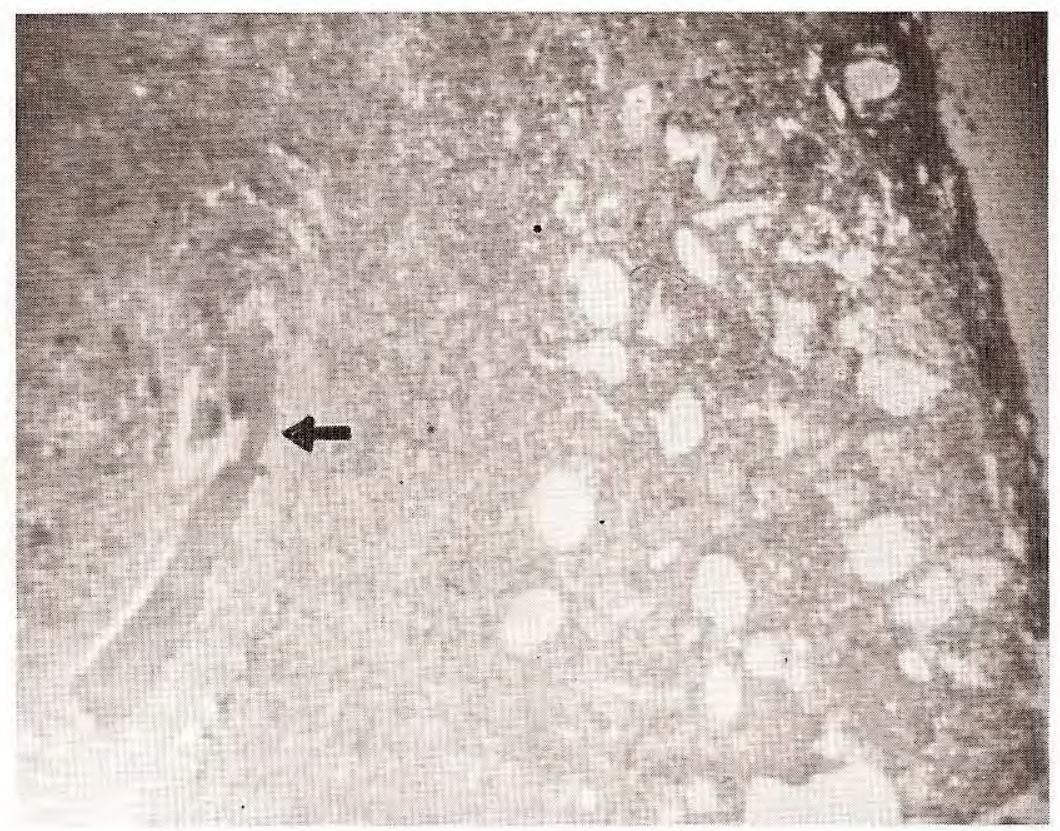

tancias que incluyen: infecciones parasitarias y micóticas del SNC, condiciones alérgicas, esclerosis múltiple, neurosífilis, meningitis tuberculosa, enfermedad de Hodgkin, reacción a cuerpos extraños, cortocircuitos neuroquirúrgicos y coriomeningitis linfocítica. También pueden producir meningitis eosinofílica algunos fármacos como el ibuprofeno o infecciones por Coxsackievirus (3).

El diagnóstico clínico de la meningoencefalitis por $A$. cantonensis se puede establecer en un paciente procedente de un área endémica, con antecedentes de exposición a los hospederos intermediarios (caracoles y moluscos) o sus secreciones, con pleocitosis eosinofílica y meningitis. La cefalea, las náuseas, los vómitos, la fiebre ligera o ausente y las anormalidades de los pares craneanos, son compatibles con este diagnóstico (10).

Este paciente procedía de La Habana, lugar donde, como mencionamos anteriormente, ha sido ya informada la presencia de este parasitismo. Sus inadecuados hábitos de vida y su alcoholismo, potenciados por el tratamiento con barbitúricos, condicionaron la exposición a una alimentación no habitual. Su enfermedad se desarrolló con un conjunto de síntomas indica- dores de infección del SNC; destacamos la cefalea, la rigidez de nuca, la leucocitosis, la fiebre moderada (sólo al inicio y al final de la evolución), los trastornos oculares (diplopía y nistagmo) y el deterioro progresivo del nivel de de conciencia y de su estado general. Sin embargo, en los análisis de sangre y de LCR no aparecieron valores altos de eosinófilos. Por tanto, a pesar de que el cuadro clínico pudo sugerir este diagnóstico, en el análisis retrospectivo, la ausencia de una pleocitosis eosinofílica del LCR pudo oscurecer el diagnóstico.

Clínicamente, en este paciente no se pudo descartar la posibilidad de una meningoencefalitis tuberculosa, encefalitis viral ni de una intoxicación exógena. Otras meningoencefalitis parasitarias resultan clínicamente indistinguibles de la angiostrongiliasis, como la neurocisticercosis, la cenuriosis, la triquinosis, la esquistosomiasis, la gnatostomiasis, la paragonimiasis o la lagoquilascariasis; pero, éstas no han sido informadas en nuestro país y presentan cuadros histopatológicos diferentes $(7,11)$. La toxocariasis, un parasitismo probable en nuestro medio (12), se puede descartar por la ausencia de manifestaciones clínicas y patológicas oculares y hepáticas; la superin- 
fección por Strongyloides stercolaris puede producir alteraciones a nivel del SNC, pero, es común el hallazgo del parásito en las criptas glandulares del intestino delgado y hasta en los bronquios, lo cual no fue encontrado en este caso.

El estudio histopatológico confirmó que la proporción de leucocitos eosinófilos en la composición del infiltrado inflamatorio de las meninges no justificaba el calificativo de meningitis eosinofílica, a pesar de estar presentes. No obstante, pudimos observar una intensa reacción granulomatosa predominantemente de células mononucleares con necrosis fibrinoide de la pared de los vasos leptomeníngeos, lo cual puede estar relacionado con la liberación de antígenos como resultado de la muerte del parásito (3) y por mecanismos de la respuesta inmune celular.

Las larvas no fueron identificadas en el estudio macroscópico del encéfalo. En los cortes histológicos, se aprecian las secciones transversales del parásito con una cutícula delgada, pared muscular con estriaciones transversas poco definidas y estructuras celulares del aparato excretor. Estos se encuentran cerca de los vasos sanguíneos y muestran cambios degenrativos.

En la figura 4 podemos identificar un corte del parásito en el interior de una arteria pulmonar rodeada por una intensa reacción inflamatoria.

Este conjunto de hallazgos histopatológicos caracterizan la migración de $A$. cantonensis en la infección aberrante del hombre y hacen poco probable el diagnóstico de otra especie de nemátodo.

Son dos las hipótesis propuestas principalmente en la explicación de la fisiopatología de la angiostrongiliasis del SNC: daño mecánico de los tejidos por la presencia y migración de los vermes y la neurotoxicidad de la proteína básica de los eosinófilos liberada como consecuencia de una respuesta inmune efectiva mediada por eosinófilos (8).
Aun cuando en nuestro paciente proponemos la posibilidad de un sistema inmune comprometido por sus inadecuados hábitos de existencia, no contamos con una explicación apropiada para la modificación de la respuesta eosinofílica característica de este parasitismo, por lo que su descripción e informe contituyen una alerta importante desde el punto de vista clínico y epidemiológico.

\section{Referencias}

1. Alicata JE. The discovery of Angiostrongylus cantonensis as a cause of human eosinophilic meningitis. Parasitol Today 1991;7:151-3.

2. Chen HT. Un nouveau nemátode pulmonairé: Pulmonema cantonensis n.g.n.sp., des rats de Canton. Ann Parasitol Hum Comp 1935;13:312-7.

3. Koo J, Pien F, Kliks MM. Angiostrongylus (Parastrongy/us) eosinophilic meningitis. Rev Infect Dis 1988;10:1115-62.

4. Cross JH. Public health importance of Angiostrongylus cantonensis and its relatives. Parasitol Today 1987;12:367-69.

5. Pascual JE, Bouli RP, Aguiar PH. Eosinophilic meningitis in Cuba caused by Angiostrongylus cantonensis. Am J Trop Med Hyg 1981;30:960-2.

6. Aguiar PH, Morera P, Pascual J. First record of Angiostrogylus cantonensis in Cuba. Am J Trop Med Hyg 1981;30:963-5.

7. Dooley JR, Neafie RC. Angiostrongyliasis cantonensis. In: Binford C, Cannor DH, eds: Pathology of tropical and extraordinary diseases. Washington, D.C.: Armed Forces Institute of Pathology, 1976:446-51.

8. Pérez $\mathbf{O}$, Capron $\mathbf{M}$, Lastre $\mathbf{M}$, Venge $\mathbf{P}$, Khalife $\mathrm{J}$, Capron A. Angiostrongylus cantonesis: role of eosinophils in the neurotoxic syndrome (Gordon-like phenomenon). Exp Parasitol 1989;68:403-13.

9. Molinari A, Donelli G. Structure and physiopathology of human eosinophils. EOS-J Immunol Immunopharmacol 1988;7:25-32.

10. Beaver PC, Jung R, Cupp EW. Beaver's clinical parasitology. 9th. edition. Philadelphia: Lea \& Fabiger, 1984:292-4.

11. Weller PF. Eosinophilic meningitis. Am J Trop Med Hyg 1993;95:250-3.

12. Montalvo AM, Espino AM, Escalante G, Finlay CM. Estudio de seroprevalencia de toxocariasis en una población infantil de la ciudad de La Habana. Rev Cubana Med Trop 1994;46:156-8. 